\title{
HIẾU QUẢ CAN THIỆP ĐA MÔ THỨC TRONG CẢI TIÊ̂N NHIỄM KHUẨN BỆNH VIÊ̂N TẠI BÊ̂NH VIỆN THANH NHÀN
}

\author{
Trần Thanh Tú*, Phạm Minh Khuê**, Doãn Ngọc Hải***
}

\section{TÓM TẮT}

Nhiễm khuẩn bệnh viện (NKBV) là một vấn đề ưu tiên tại các bệnh viện. Xây dựng và triển khai các can thiệp giúp kiểm soát NKBV đóng vai trò quan trọng trong đảm bảo chất lượng bệnh viện và an toàn ngườ bệnh. Mục tiêu của nghiên cứu nhằm đánh giá hiêu quả can thiệp đa mô thức trong cải thiện nhiếm khuẩn bênh viên tai Bệnh viện Thanh Nhàn. Nghiên cứu can thiệp đảnh giá trước-sau không có nhóm chứng tại bênh viện Thanh Nhàn từ 2018 đến 2020. Can thiệp tiến hành cải thiện quy trình vệ sinh tay, quy trình thay băng vết thương và đặt catheter tĩnh mạch ngoại vi. Tình trạng NKBV trước và sau can thiệp được đánh giá, thu thập thông qua biểu mẫu được thiết kế sẵn. Kết quả cho thấy tỷ lệ NKBV từ $6,0 \%$ trước can thiệp giảm còn $2,2 \%$ sau can thiệp $(p<0,01)$, hiệu quả can thiệp đạt $63,3 \%$. Mật độ NKBV/1000 ngày nằm viện giảm từ 5,12 xuống 2,60 . Nhiễm khuẩn hô hấp trên là dạng NKBV phổ biến nhất (7/14 trường hợp, 50,0\%). Mồ hình hồi quy đa biến cho thây những người bệnh điều trị nội trú tại bệnh viện sau can thiệp chỉ có khả năng mắc NKBV bằng 0,19 lần so với người bệnh điêuu trị nội trú tại bệnh viện giai đoạn trước can thiệp $(\mathrm{OR}=0,19,95 \% \mathrm{CI}=0,09-0,37, \mathrm{p}<0,01)$. Mô hình can thiêp đã có hiêuu quả giúp cải thiên tình trang NKBV tại bệnh viện Thanh Nhàn. Việc xây dựng các chiến lược giúp cải thiện hiệu quả và đảm bảo tính bền vững của mô hình là điều cân thiết và cần được nghiên cứu trong tương lai.

Tư khóa: nhiễm khuẩn bệnh viện, can thiệp, đa mô thức

\section{SUMMARY}

\section{EFFECTIVENESS OF MULTIMODAL INTERVENTIONS IN IMPROVING HOSPITAL-ACQUIRED INFECTION IN THANH NHAN HOSPITAL}

Nosocomial infections are a priority issue in hospitals. Developing and implementing interventions to help control hospital-acquired infections plays an important role in ensuring hospital quality and patient safety. This study evaluated the effectiveness of multimodal interventions in improving nosocomial infections at Thanh Nhan Hospital. A before-after intervention study without a control group was implemented at Thanh Nhan hospital from 2018 to 2020. The intervention was conducted to improve

*Bênh viện Thanh Nhàn

**Trường Đại họ Y Dược Hải Phòng

***Viên sức khỏe Nghề nghiêp \& Môi trường

Chịu trách nhiệm chính: Trân Thanh Tú

Email: tranthanhtu78bvtn@gmail.com

Ngày nhận bài: 7.9.2021

Ngày phản biên khoa hoc: 27.10.2021

Ngày duyệt bài: 9.11.2021 hand hygiene, wound dressing and peripheral venous catheters. The status of hospital-acquired infections before and after the intervention was assessed and collected through a structured form. Results showed that the rate of nosocomial infections from $6.0 \%$ before the intervention decreased to $2.2 \%$ after the intervention $(p<0.01)$, the effect size was $63.3 \%$. Density of hospital admissions/1000 days of hospital stay decreased from 5.12 to 2.60 after the intervention. Upper respiratory tract infection was the most common form of hospital-acquired infection (7/14 cases, $50.0 \%$ ). Multivariable regression model showed that inpatients treated at the hospital after the intervention were only 0.19 times more likely to have nosocomial infections than inpatients at the hospital in the pre-intervention period (OR $=0.19,95 \% \mathrm{CI}=0.09$ $0.37, p<0.01)$. The intervention model had been effective in improving hospital-acquired infections at Thanh Nhan hospital. Developing strategies to improve the efficiency and ensure the sustainability of the model is essential and needs to be studied in the future.

Keywords: nosocomial infection, intervention, multimodality

\section{I. ĐĂT VẤN ĐỀ}

Nhiễm khuẩn bệnh viện (NKBV) là một trong những vấn đề y tế công cộng hàng đâu trên toàn thế giới [1]. NKBV xảy ra sau khi người bệnh nhập viện và được coi là một chỉ số quan trọng đánh giá chất lượng bệnh viện, khả năng tổ chức quản lý và khả năng đảm bảo an toàn cho người bệnh của cơ sở y tế [2]. NKBV lan truyền bằng nhiều con đường thông qua bề mặt (đặc biệt là tay), nước, không khí, đường tiêu hóa và phẫu thuật. Trong đó, vai trò của nhân viên y tế (NVYT) trong việc lây truyền NKBV là rất lớn. NVYT có thể gây nhiếm khuẩn cho người bệnh thông qua quá trình thu thập, xử lý và loại bỏ bệnh phẩm, xử lý và loại bỏ trang thiết bị y tế cững như trong quá trình tương tác trực tiếp giữa người bệnh với NVYT tại thời điểm khám bệnh. Nhiều NKBV được gây ra bởi sự lan truyền từ người bệnh này sang người bệnh khác thông qua NVYT $[3,4]$. Vì vậy, các can thiệp tập trung tăng cường giám sát nhằm tăng sự tuân thư thực hành KSNK của NVYT trong bệnh viện đóng vai trò trung tâm cho các chiến lược giảm thiểu tỷ lệ mắc KNBV [5].

Bệnh viện Thanh Nhàn là bênh viên đa khoa hạng I. Theo báo cáo giám sát của khoa Kiểm soát nhiễm khuẩn bệnh viện Thanh Nhàn tháng 10/2017 tỷ lệ NKBV là 3,66\%, năm 2018 có 5,9\% người bệnh nội trú mắc NKBV, tăng lên $6,1 \%$ 
trong năm 2019. Cơ sở vật chất của bênh viện hiện tại đang chật chội, chưa đáp ứng được nhu cầu thực sự của bệnh viên hạng I về diện tích phục vụ người bệnh do số lượng người bệnh quá tải, cũng như vị trí để thực hiện tốt công tác KSNK bệnh viện. Những khó khăn này là những yếu tố thuân lợi làm tăng nguy cơ NKBV tại bênh viện Thanh Nhàn. Giai đoạn 2019-2020, bệnh viện triển khai can thiệp đa mô thức nhằm cải thiện tuân thủ vệ sinh tay, quy trình thay băng vết thương và đặt catheter tĩnh mạch ngoại vi. Nghiên cứu này được tiến hành nhằm "Đánh giá hiệu quả can thiệp cải thiện nhiếm khuẩn bệnh viện tại Bệnh viện Thanh Nhàn".

\section{II. ĐỐI TƯƠNG VÀ PHƯƠNG PHÁP NGHIÊN CỨU}

2.1 Đối tượng nghiên cứu. Người bệnh điều trị nội trú tại Bệnh viện Thanh Nhàn, Hà Nội.

- Tiêu chuẩn tuyển chọn: Người bệnh đủ tiêu chuẩn nghiên cứu là những người bệnh nằm điều trị nội trú, có thời gian nhập viện $>48$ giờ và có măt tai thời điểm điều tra.

\section{- Tiêu chuân loại trừ}

+) Người bệnh có thời gian nằm viện dưới 48 giờ, người bệnh điều trị ngoại trú.

+) Người bệnh đang ủ bệnh một bệnh nhiễm trùng khi nhập viện, phát hiện người bệnh này chủ yếu dựa vào dấu hiệu bất thường về cận lâm sàng như $X Q$, xét nghiệm máu ...và khám lâm sàng có biểu hiện của bểnh nhiễm khuẩn

\subsection{Thời gian và địa điểm nghiên cứu}

Nghiên cứu được tiến hành tại Bệnh viện Thanh Nhàn - Hà Nội từ tháng 1/2018 đến tháng 9/2020. Giai đoạn 1: Đánh giá trước can thiệp tháng 8/2018-8/2019. Giai đoạn 2: Can thiệp từ tháng $8 / 2019$. Giai đoạn 3: Đánh giá sau can thiệp tháng 9/2020

2.3 Thiết kế nghiên cứu. Nghiên cứu can thiệp, có đánh giá trước và sau không có nhóm chứng

2.4 Cỡ mẩu và chọn mẫu: Cỡ mẫu xác định tỷ lệ NKBV: được thực hiện trên toàn bộ người bệnh nội trú tại các khoa được chọn tại bệnh viện có thời gian nằm viện trên 48 giờ tính đến thời điểm đánh giá NKBV. Tổng cộng có 712 người bệnh năm 2018 (đánh giá ngày 29/8/2018), 751 người bệnh năm 2019 (đánh giá ngày 27/7/2019) và 647 người bệnh năm 2020 (đánh giá ngày 30/9/2020). Chọn người bệnh theo phương pháp chọn mẫu thuận tiện. Chọn tất cả người bệnh có đủ các tiêu chuẩn trên từ thời điểm tiến hành nghiên cứu.

2.5 Can thiệp. Can thiệp tiến hành cải thiện quy trình vệ sinh tay, quy trình thay băng vết thương và đặt catheter tĩnh mạch ngoại vi thông qua các hoạt động:

- Bổ sung, hoàn thiện, ban hành quy trình

- Trang bị phương tiện, vật dụng cần thiết

- Tập huấn, đào tạo

- Tănng cường, nâng cao chất lượng hoạt động, giám sát

\subsection{Cách thức thu thập thông tin đánh} giá NKBV

- Bác sĩ điều trị

+ Tại bệnh viện, bác sĩ điều trị xem xét bệnh sử, triệu chứng lâm sàng, cận lâm sàng của người bênh đủ tiêu chuẩn nghiên cứu, phát hiện người bệnh nghi ngờ/xác định nhiễm khuẩn bênh viện. Bồ sung các xét nghiệm, thủ thuật cần thiết.

+ Cùng bác sĩ khoa Kiểm soát nhiễm khuẩn thảo luận về những người bệnh nghi ngờ/chẩn đoán nhiễm khuẩn bệnh viện. Những trường hợp chưa thống nhất chẩn đoán được tham khảo ý kiến của bác sĩ trực tiếp điều trị và bác sĩ trưởng/phó khoa.

+ Điên thông tin về chẩn đoán bệnh, thủ thuật, kháng sinh vào phiếu giám sát và hoàn thành phiếu giám sát với những người bệnh xuất viện.

- Điêuu dưỡng giám sát

+ Lập danh sách tất cả người bệnh có mặt trong khoa theo mẫu, xác định người bệnh đủ tiêu chuẩn điều tra và người bệnh ra viện trong ngày.

+ Hoàn thành phần hành chính phiếu giám sát NKBV với những người bệnh đủ tiêu chuẩn giám sát. Phiếu giám sát được gắn vào trang cuối của mỗi bệnh án để bổ sung thông tin trong thời gian giám sát.

+ Theo dõi, ghi những dấu hiệu nghi ngờ nhiễm khuẩn vào phiếu theo dõi người bệnh hàng ngày, thông báo cho bác sĩ giám sát triệu chứng lâm sàng của người bệnh nghi ngờ NKBV.

+ Thông báo với bác sĩ giám sát người bệnh ra viện trong ngày.

2.7 Phân tích số liệu. Số liệu được nhập vào phần mềm Epidata, phân tích bằng phẩn mềm Stata 15.0, lấy kết quả phân tích tần số và tỷ lệ \%, để mô tả thực trạng NKBV trước và sau can thiệp, kết hợp với sử dụng test kiểm định $\mathrm{x} 2$, tỷ suất chênh OR, với khoảng tin cậy $95 \%$ để so sánh sự khác biệt giữa các tỷ lệ. Phân tích mô hình hồi quy logistic đơn biến, đa biến để tìm sự liên quan của các yếu tố liên quan đến tỷ lề NKBV. Sử dụng công thức tính chỉ số hiệu quả để phân tích hiệu quả can thiệp trong nghiên cứu này.

2.8 Đạo đức nghiên cứu. Nghiên cứu đã được Hội đồng Đạo đức Bệnh viện Thanh Nhàn thông qua. Nghiên cứu được sự đồng ý của lãnh đạo bệnh viện và các khoa nghiên cứu. Đảm bảo sự tham gia tự nguyện của các đối tượng nghiên cứu. 


\section{KẾT QUẢ NGHIÊN CỨU}

Nghiên cứu tiến hành đánh giá sau can thiêp ngày 30/9/2020 trên 647 người bệnh nội trú. Đầy là tất cả người bệnh nội trú điều trị tại bệnh viện ở thời điểm này. Có sự khác biệt về giới tính, khoa điều trị, tình trạng mắc bệnh tim mạch, đái tháo đường và tăng huyết áp, tình trạng đặt nội khí quản, đặt ống thông tiểu và đặt đường truyền tĩnh mạch máu ngoại vi, số lượng thủ thuật và tình trạng phẫu thuật giữa hai lẩn đánh giá $(p<0,05)$.

Bảng 1. Tình trạng mắc nhiễm khuẩn bệnh viện

\begin{tabular}{|c|c|c|c|c|c|c|}
\hline \multirow{2}{*}{$\begin{array}{c}\text { Mắc nhiếm khuấn } \\
\text { bệnh viện }\end{array}$} & \multicolumn{2}{|c|}{ Trước can thiệp $(\mathrm{n}=1463)$} & \multicolumn{2}{|c|}{ Sau can thiệp $(\mathrm{n}=647)$} & \multirow{2}{*}{ p-value } & $\begin{array}{c}\text { CSHQ } \\
(\%)\end{array}$ \\
\cline { 2 - 6 } & $\mathrm{n}$ & $\%$ & $\mathrm{n}$ & & \\
\hline Không & 1375 & 94,0 & 633 & 97,8 & \multirow{2}{*}{$<0,01$} & \multirow{2}{*}{63,3} \\
\hline Có & 88 & 6,0 & 14 & 2,2 & \\
\hline
\end{tabular}

*CSHQ: Chỉ số hiệu quả

Bảng 1 cho thấy tỷ lệ NKBV từ $6,0 \%$ trước can thiệp giảm còn $2,2 \%$ sau can thiệp $(p<0,01)$, hiệu quả can thiệp đạt $63,3 \%$.

Bảng 2. Tình trạng mắc nhiễm khuẩn bệnh viện

\begin{tabular}{|c|c|c|c|c|c|}
\hline \multirow{2}{*}{$\begin{array}{l}\text { Loại nhiễm khuẩn bệnh } \\
\text { viện }\end{array}$} & \multicolumn{2}{|c|}{ Trước can thiệp ( $n=1463)$} & \multicolumn{2}{|c|}{ Sau can thiệp $(n=647)$} & \multirow{2}{*}{$\begin{array}{c}\text { p- } \\
\text { value }\end{array}$} \\
\hline & $\mathrm{n}$ & $\%$ & $\mathrm{n}$ & $\%$ & \\
\hline Nhiểm khuấn vết mố & 33 & 37,5 & 2 & 14,3 & \multirow{7}{*}{0,12} \\
\hline Nhiêm khuấn huyết & 6 & 6,8 & 2 & 14,3 & \\
\hline Nhiểm khuấn hô hấp trên & 21 & 23,9 & 7 & 50,0 & \\
\hline Viêm phối bệnh viện & 12 & 13,6 & 0 & 0,0 & \\
\hline Nhiềm khuấn tiết niệu & 7 & 8,0 & 2 & 14,3 & \\
\hline Nhiềm khuấn da, mô mềm & 5 & 5,7 & 1 & 7,1 & \\
\hline Nhiêm khuấn khác & 4 & 4,6 & 0 & 0,0 & \\
\hline
\end{tabular}

Bảng 2 cho thấy sau can thiệp, nhiễm khuấn hô hấp trên là dạng NKBV phố biến nhất $(7 / 14$ trường hợp, 50,0\%). Vẫn còn các dạng NKBV như nhiễm khuẩn vết mổ, nhiễm khuẩn hô hấp trên, nhiễm khuẩn huyết, nhiễm khuẩn tiểt niệu và nhiễm khuẩn da, mô mềm, dù chỉ có 1-2 trường hợp. Bảng 3 cho thây sau can thiệp, mật độ NKBV/1000 ngày nằm viện giảm từ 5,12 xuống 2,60. Hiệu quả can thiệp là $49,1 \%$.

Bảng 3. Mật độ mắc nhiễm khuẩn bệnh viện

\begin{tabular}{|c|c|c|c|c|c|c|c|}
\hline \multirow[b]{2}{*}{$\begin{array}{c}\text { Đăc } \\
\text { điểm }\end{array}$} & \multicolumn{3}{|c|}{ Trước can thiệp } & \multicolumn{3}{|c|}{ Sau can thiệp } & \multirow[b]{2}{*}{ CSHQ } \\
\hline & $\begin{array}{l}\text { Số ca } \\
\text { nhiếm } \\
\text { khuẩn }\end{array}$ & $\begin{array}{l}\text { Số ngày } \\
\text { nằm } \\
\text { viện }\end{array}$ & $\begin{array}{c}\text { Số nhiềm } \\
\text { khuẩn/1.000 } \\
\text { ngày nằm viện }\end{array}$ & $\begin{array}{l}\text { Số ca } \\
\text { nhiếm } \\
\text { khuẩn }\end{array}$ & $\begin{array}{c}\text { Số ngày } \\
\text { nằm viện }\end{array}$ & $\begin{array}{c}\text { Số nhiềm } \\
\text { khuẩn/1.000 } \\
\text { ngày nằm viện }\end{array}$ & \\
\hline $\begin{array}{l}\text { NKBV } \\
\text { chung }\end{array}$ & 88 & 17229 & 5,12 & 14 & 5393 & 2,60 & $49,1 \%$ \\
\hline
\end{tabular}

*CSHQ: Chỉ số hiệu quả

Sau can thiệp có $11 / 14$ mẫu được cấy vi sinh. Có $4 / 11$ mẫu $(36,4 \%)$ âm tính, $4 / 11$ mẫu $(36,4 \%)$ dương tính với Klebsiella pneumoniae và 3 mẫu dương tính với Acinetobacter spp. (Bảng 4)

Bảng 4. Kêt quả cấy vỉ sinh

\begin{tabular}{|c|c|c|c|c|c|}
\hline \multirow{2}{*}{ Đặc điểm } & \multicolumn{2}{|c|}{ Trước can thiệp (n=88) } & \multicolumn{2}{c|}{ Sau can thiệp (n=14) } & \multirow{2}{*}{ p-value } \\
\cline { 2 - 5 } & $\mathbf{n}$ & $\mathbf{\%}$ & $\mathbf{n}$ & $\mathbf{\%}$ & \\
\hline Cấy vi sinh: Có & 36 & 40,9 & 11 & 78,6 & \multirow{2}{*}{$<0,01$} \\
\hline Không & 52 & 59,1 & 3 & 21,4 & \\
\hline Kết quả: Âm tính & 18 & 50,0 & 4 & 36,4 & $<0,01$ \\
\hline Pseudomonas aeruginosa & 10 & 27,8 & 0 & 0,0 & \\
\hline Klebsiella pneumoniae & 5 & 13,9 & 4 & 36,4 & \\
\hline Acinetobacter spp. & 0 & 0,0 & 3 & 27,2 & \\
\hline S. aureus & 3 & 8,3 & 0 & 0,0 & \\
\hline
\end{tabular}

Kết quả mô hình hồi quy đa biến đánh giá tác động của can thiệp ở bảng 5 cho thấy, can thiệp có thể làm giảm $81 \%$ khả năng mắc NKBV, hay nói cách khác, những người bệnh điều trị nội trú tại bệnh viện sau can thiệp chỉ có khả năng mắc NKBV bằng 0,19 lần so với ngưới bệnh điêu trị nội trú tại bệnh viện giai đoạn trước can thiệp $(\mathrm{OR}=0,19,95 \% \mathrm{CI}=0,09-0,37, \mathrm{p}<0,01)$. 


\begin{tabular}{|c|c|c|c|c|c|c|}
\hline \multirow{2}{*}{ Đặc điểm } & \multicolumn{3}{|c|}{$\begin{array}{c}\text { Nguy cơ nhiêm khuấn bệnh viện } \\
\text { (chưa hiệu chỉnh) }\end{array}$} & \multicolumn{3}{|c|}{$\begin{array}{l}\text { Nguy cơ nhiêm khuấn bênh viện } \\
\text { (đã hiêu chỉnh)* }\end{array}$} \\
\hline & OR & $95 \% \mathrm{CI}$ & p-value & OR & $95 \% \mathrm{CI}$ & p-value \\
\hline Trước can thiệp & 1 & & & 1 & & \\
\hline Sau can thiêpp & 0,35 & $0,20-0,61$ & $<0,01$ & 0,19 & $0,09-0,37$ & $<0,01$ \\
\hline
\end{tabular}

*Mô hình hiệu chỉnh: thông tin chung của người bệnh, Khoa, bệnh hiện mắc, thủ thuật can thiệp, tình trạng phẫu thuật, thời gian nằm viện

\section{BÀN LUẬN}

Nghiên cứu cho thấy, trước can thiệp, tỷ lệ NKBV tại bệnh viện Thanh Nhàn đang ở mức cao. Điều này có thể lí giải do bệnh viện Thanh Nhàn là bệnh viện tuyến trên của Hà Nội, nhận bệnh nhân từ nhiều vùng của Hà Nội với nhiều tình trạng bệnh nặng, phức tạp; sử dụng nhiều hơn những phương tiện chẩn đoán và điều trị xâm nhập, số lượng bệnh nhân ngày càng đông với tình trạng quá tải liên tục dẫn đến tỷ lệ NKBV của bệnh viện Thanh Nhàn tăng so với những năm trước và cao hơn nhiều bệnh viện khác. Theo điều tra cắt ngang NKBV tại bệnh viện Thanh Nhàn 10/2017 tỷ lệ NKBV là 3,58\%, năm 2018 có $5,9 \%$ người bệnh nội trú mắc NKBV, tăng lên $6,1 \%$ trong năm 2019. Như vậy, tỷ lệ NKBV tại bệnh viện đang có xu hướng tăng lển. Đây là một thực trạng đáng báo động gây rất nhiều khó khăn cho cổng tác KSNK. Bởi vậy công tác KSNK cần được đầy mạnh để giải quyết tình hình nhiễm khuẩn bệnh viện.

Đối với quá trình can thiệp, trong nghiên cứu này, chúng tôi áp dụng cách tiếp cận đa mô thức nhằm tối ưu hiệu quả và tính bền vững của mô hình can thiệp. Các bằng chứng hiện tại ủng hộ chiến lược đa mô thức trong xầy dựng các chương trình can thiệp KSNK [6]. Năm 2009, WHO đã công bố hướng dẫn thực hiện và đánh giá các chương trình vệ sinh tay trong các cơ sở y tế [7]. Hướng dẫn này xác định năm thành phần cân được thực hiện cụ thể: sát khuẩn tay bằng cồn tại điểm chăm sóc hoặc được thực hiện bởi NVYT, đào tạo và giáo dục, phản hồi quan sát và kết quả hoạt động, các gợi ý nhắc nhở (ví dụ: áp phích), và hỗ trợ hành chính/ môi trường/ thể chể. Các hướng dấn của WHO đã được phổ biến rộng rãi trên toàn thế giới và được báo cáo là có ảnh hưởng lớn tới công tác KSNK tại các bệnh viện [8]. Can thiệp tại bệnh viện áp dụng nguyên lý đa mô thức này trong cải thiện tuân thủ vệ sinh tay, quy trình thay băng vết thương và đặt catheter tĩnh mạch ngoại vi.

Kết quả đánh giá sau can thiệp cho thây, tỷ lệ NKBV từ 6,0\% trước can thiệp giảm còn $2,2 \%$ sau can thiệp $(p<0,01)$, hiệu quả can thiệp dạt
63,3\%. Sau can thiêp, nhiễm khuẩn hô hấp trên là dạng NKBV phổ biến nhất (7/14 trường hợp, $50,0 \%)$. Vẫn còn các dạng NKBV như nhiềm khuẩn vết mổ, nhiễm khuẩn huyết, nhiễm khuẩn tiết niệu và nhiếm khuẩn da, mô mềm, dù chỉ có 1-2 trường hợp. Sau can thiệp, mật độ $\mathrm{NKBV} / 1000$ ngày nằm viện giảm từ 5,12 xuống 2,60 . Hiệu quả can thiệp là 49,1\%.

Mô hình hồi quy đa biến đánh giá tác động của can thiệp cho thấy, can thiệp có thể làm giảm $81 \%$ khả năng mắc NKBV, hay nói cách khác, những người bệnh điều trị nội trú tại bệnh viện sau can thiệp chỉ có khả năng mắc NKBV bằng 0,19 lần so với người bệnh điều trị nội trú tại bệnh viện giai đoạn trước can thiệp ( $\mathrm{OR}=0,19,95 \% \mathrm{CI}=0,09-0,37, \mathrm{p}<0,01)$. Đáng chú ý trong bối cảnh thực hiện nghiên cứu, ngoài can thiệp được thực hiện trong nghiên cứu này, không có can thiệp nào về KSNK được thực hiện. Do đó, sự thay đổi về tỷ lệ NKBV có thể được cho là do có sự tác động sâu rộng của can thiệp này tới việc hình thành kiến thức, thái độ và thói quen của NVYT, từ đó làm giảm nguy cơ mắc NKBV cho người bệnh.

Nghiên cứu cũng còn một số hạn chế. Nghiên cứu chọn chủ đích 1 bệnh viện, do đó có thể kết quả nghiên cứu không phản ánh cho các bệnh viện khác. Nghiên cứu can thiệp thực hiện so sánh "trước - sau", chưa có nhóm đối chứng để so sánh kết quả nghiên cứu, nên có thể có một số yếu tố nhiễu ảnh hưởng đến kết quả nghiên cứu.

\section{KẾT LUÂNN}

Mô hình can thiệp đa mô thức trong cải thiện tuân thủ vệ sinh tay, quy trình thay băng vết thương và đặt catheter tĩnh mạch ngoại vi đã có hiệu quả giúp cải thiện tình trạng NKBV tại bệnh viện Thanh Nhàn. Việc xây dựng các chiến lược giúp cải thiện hiệu quả và đảm bảo tính bền vững của mố hình là điều cần thiết và cần được nghiên cứu trong tương lai.

\section{TÀI LIẸU THAM KHẢO}

1. Monegro AF, Muppidi $V$, Regunath H. Hospital Acquired Infections. StatPearls. Treasure Island 
(FL): StatPearls Publishing. Copyright (C) 2021, StatPearls Publishing LLC.; 2021.

2. Boev C, Kiss E. Hospital-Acquired Infections: Current Trends and Prevention. Critical care nursing clinics of North America. 2017;29(1):51-65.

3. Asfaw N. Knowledge and practice of nurses towards prevention of hospital acquired infections and its associated factors. International Journal of Africa Nursing Sciences. 2021;15:100333.

4. Bayleyegn B, Mehari A, Damtie D, Negash M. Knowledge, Attitude and Practice on HospitalAcquired Infection Prevention and Associated Factors Among Healthcare Workers at University of Gondar Comprehensive Specialized Hospital, Northwest Ethiopia. Infection and drug resistance. 2021; 14:259-66.
5. Organization WH. Guidelines on core components of infection prevention and control programmes at the national and acute health care facility level. Geneva: World Health Organization; 2016.

6. Organization WH. Infection prevention and control assessment framework at the facility level. World Health Organization; 2018.

7. Organizationx WH. World Health Organization Guidelines on Hand Hygiene in Health Care 2009 [Available from: www.who.int/ gpsc/5may/tools/ 9789241597906/en/

8. Mathai E, Allegranzi B, Kilpatrick C, Bagheri Nejad S, Graafmans W, Pittet D. Promoting hand hygiene in healthcare through national/subnational campaigns. The Journal of hospital infection. $2011 ; 77(4): 294-8$.

\section{ĐĂC ĐIỂM LÂM SÀNG, CÂ̂N LÂM SÀNG BÊNNH NHÂN XEP ĐA TẦNG CộT SỐNG NGỰC VÀ THẮT LƯNG DO LOÃNG XƯƠNG ĐIỀU TRI BẰNG PHƯƠNG PHÁP BƠM CEMENT SINH HỌC}

\section{Trịnh Bá Thắng*, Hoàng Gia Du*, Nguyễn Văn Trung*, Vũ Xuân Phước*, Nguyễn Đức Hoàng*, Lê Đăng Tân*, Trịnh Minh Đức*, Phan Bá Quỳnh*. \\ SUBCLINICAL FEATURES}

\section{TÓM TẮT}

Mục đích: Mô tả đặc điểm lâm sàng, cân lâm sàng của các bệnh nhân xẹp đa tâng cột sống ngực, thắt lưng được điều trị bằng phương pháp bớm cement sinh học. Phương pháp nghiên cứu: Mô tả cắt ngang 28 trường hợp xẹp đa tầng cột sống ngực thắt lưng được điêu trị bằng phương pháp bơm cement sinh học đa tầng tại Bệnh viện Bạch Mai từ tháng 01 năm 2019 đến tháng 6 năm 2021. Kết quả: Tỷ lệ nữ/ nam: 8.35, tuổi trung bình 70.5 tuổi (44-86), $100 \%$ bênh nhân có bênh nền. Triêu chứng chính: đau đột ngột tại cột sống do chấn thương nhẹ hoặc tự nhiên kèm hạn chế vận động do đau, VAS trung bình 7.04 điểm (6-9), tổng số 103 đốt xẹp mới, vị trí tổn thương nhiều nhất ở $\mathrm{T}_{12}$ (17 đốt xẹp), chủ yếu là xep hình chêm (51.5\%), 75\% bệnh nhẩn có biến dạng cột sống- T-Score trung bình -3.89. Kết luân: Xep đa tầng cột sống ngực thắt lưng do loãng xưởng chủ yếu ở bệnh nhân cao tuổi, nữ giới, có bệnh lý nền, khởi phát sau một chấn thương nhẹ hoặc tự nhiên, thường đau kéo dài, tỷ lệ biến dạng cột sống cao, mức độ loãng xương nặng.

Tư Khóa: xẹp đa tầng cột sống, lâm sàng và cận lâm sàng.

\section{SUMMARY}

MULTILEVEL VERTEBROPLASTY: CLINICAL,

*Bênh viên Bach Mai.

Chịu trách nhiệm chính: Trịnh Bá Thắng

Email: dr.trinhbathang2502@gmail.com

Ngày nhận bài: 10.9.2021

Ngày phản biên khoa hoc: 28.10.2021

Ngày duyệt bài: 11.11.2021
Objectives: Analyzing clinical, subclinical features of the patients was diagnosed osteoporosis multilevel vertebral compression fractures (OMVCFs) was treated by percutaneous vertebroplasty (VP). Methods: Cross- sectional descriptive retrospective and prospective study of 28 OMVCFs underwent VP in Bach Mai hospital from 1/2019 to 6/2021. Result: The female-male ratio is 8.35 with mean age of 70.5 (4486 years old), all of the patients have background, the patients frequently presented with sudden onset of pain in proportion to VCFs because of light trauma or natural happening with decreasing of spinal mobility because of pain, the mean of VAS score is $7.04, T_{12}$ is the most in 103 new injuried segments (17 segments), fracture type: wedge fratures is the highest ratio $(51,5 \%)$, the spinal deformity ratio is $75 \%$, mean TScore is -3.89 . Conclusion: Osteoporosis multilvel vertebral compression fracture freaquently present in elder woman underwent a light injury or have not reason, frequently prolonged pain and severe osteoporosis. The deformity ratio and background disease ratio is high.

Key words: multilevel vertebral compression fractures, clinical and subclinical features.

\section{I. ĐĂT VẤN ĐỀ}

Xẹp thân đốt sống (XTĐS) là bệnh lý gây giảm chiều cao cột sống kèm theo đau lưng dai dẳng ${ }^{1}$. Ngày nay, cùng với sự phát triển xã hội, xẹp thân đốt sống xảy ra ngày càng phổ biến. Có khoảng 1.5 triệu trường hợp XTĐS xảy ra mỗi năm ở Mỹ, thường xảy ra phổ biến ở nhóm người cao tuổi, khoảng $25 \%$ trong tổng số phụ nữ sau 